\title{
Editor de Cidades Civitas Città
}

\author{
Daniel Nehme Müller¹, Laurent Le Avner Quevedo², Andressa Cruz Nepomuceno ${ }^{3}$, \\ Luciano Soares $^{4}$, Juarez Dubois da Costa ${ }^{5}$, Maribel Suzane Selli ${ }^{6}$ e Margarete Axt $^{6}$ \\ Conexum Ltda. ${ }^{1}$
}

Curso de Jogos Digitais, Universidade do Vale do Rio dos Sinos (UNISINOS) ${ }^{2}$

Curso de Ciência da Computação, Universidade do Vale do Rio dos Sinos (UNISINOS) ${ }^{3}$

Curso Produção Multimídia Digital, Universidade do Sul de Santa Catarina (UNISUL) ${ }^{4}$ Laboratório de Estudos em Linguagem, Interação e Cognição, Universidade Federal do Rio Grande do Sul (UFRGS) ${ }^{5}$

Programa de Pós Graduação em Informática na Educação, Universidade Federal do Rio Grande do Sul (UFRGS) ${ }^{6}$

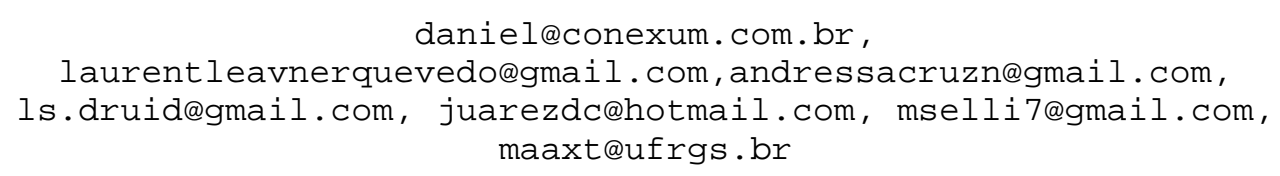

\begin{abstract}
The city editor Città develops the digital side of inventing cities promoted by Civitas Project, Faculty of Education / UFRGS. Citta is a free GPL software which allows the construction of a three dimensional city using Java and SQLite database. The city is monitored by an intelligent agent that uses Bayesian inference as well as recognition and speech synthesis. In this paper is being presented the expansion of the Città for use of multiplayer, text/voice chat and the rewriting the system in Blender, using multiplayer features and web access.
\end{abstract}

Resumo. $O$ editor de cidades Città desenvolve o lado digital de invenção de cidades promovido pelo Projeto CIVITAS, da Faculdade de Educação/UFRGS. Città é um software livre GPL que permite a construção de uma cidade tridimensional usando Java e banco de dados SQLite. Tem como contexto de aplicação turmas de quarto ano de Escolas Municipais de Ensino Fundamental de um Município da Região do Vale do Taquari no Estado do Rio Grande do Sul. Neste artigo estarão sendo apresentadas, além da versão Java, também sua versão reescrita do sistema em Blender, com a exploração de recursos multijogador, chat por voz e texto, além do seu uso potencial em sistemas android e navegadores web.

\section{Introdução}

O Projeto Città Cosmopolita - Simuladores de Cidades em Redes ${ }^{1}$ visa à pesquisa e ao desenvolvimento dos módulos de comunicação, interação e geolocalização do jogo computacional educacional e simulador de cidades Città [Oliveira et al, 2009], que vem sendo desenvolvido pelo LELIC (Laboratório de Estudos em Linguagem, Interação e Cognição da Faculdade de Educação da UFRGS) em parceria com a empresa CONEXUM. Città é um software livre com licença GPL com fontes disponibilizados no SourceForge².

Os novos módulos concebidos para o Città contemplam a interação entre as cidades

1 Projeto financiado pelo CNPq - Conselho Nacional de Desenvolvimento Científico e Tecnológico.

2 http://sourceforge.net/projects/civitas/ 
virtuais construídas pelos estudantes, o uso do sistema na web e em dispositivos móveis, a comunicação com o assistente inteligente Maga Vitta baseado na análise do estado afetivo (emoção no texto e na voz), e na geolocalização das cidades. O desenvolvimento da assistente inteligente está sendo realizado em parceria ainda com pesquisadores da UNISC e UNIPAMPA, e a plataforma web com geolocalização está sendo desenvolvida com parceria com pesquisadores da UNEB. O interesse da CONEXUM está no desenvolvimento de novos sistemas para dispositivos móveis, visando interfaces facilitadas por assistentes. Ao longo do projeto as escolas atendidas pelo LELIC através do Projeto CIVITAS - Cidades Virtuais com Tecnologias para Aprendizagem e Simulação [Axt e Martins, 2008] terão um benefício direto com o uso do jogo em suas atividades pedagógicas.

Neste artigo serão abordados a contextualização dos jogos de simulação no ensino (seção 2), a apresentação geral do Città (seção 3), o agente inteligente (seção 4) e os novos recursos Blender que estão sendo explorados na nova versão (seção 5). Por fim, algumas considerações finais sobre o desenvolvimento e futuras aplicações derivadas do projeto.

\section{Jogos de simulação no ensino}

Os jogos digitais já vêm sendo pesquisados como recursos de ensino há muitos anos, em diversas disciplinas. Podemos encontrar jogos específicos no ensino de Biologia [Guterres et al, 2003], Física [Hornes et al, 2009] ou Geografia [Pereira et al, 2011]. Ainda em Geografia, encontramos o uso de jogos comerciais, como o SimCity [Tavares, 2012] ou livres, como o LinCity [Albuquerque, 2009]. Este último foi experimentado em várias disciplinas, mas sem muito sucesso, devido à falta de um planejamento adequado com o software.

Progressivamente os jogos de simulação, principalmente digitais, estão evoluindo rapidamente. Os pesquisadores que investigam o uso de jogos de interação e imaginação como o RPG digital aplicado a disciplinas [Araújo e Simon, 2008], jogos comerciais como The Sims [Oliveira, 2011], jogos para web [Tarouco et al, 2004] são unânimes em considerar a importância do preparo dos professores e o bom planejamento da aula como pontos de sucesso do uso de qualquer jogo digital. Infelizmente jogos educacionais desenvolvidos com professores e estudantes ainda são raros, sendo encontrados jogos de entretenimento adaptados a situações de sala de aula.

\section{O jogo de simulação Città}

Dentro de contextos de jogos de simulação, Città é a versão digital do simulacro da cidade que ocorre na sala de aula com alunos do $4^{\circ}$ ano do ensino fundamental atendidos pelo Projeto CIVITAS. As crianças reinventam cidades imaginárias onde eles são cidadãos e tornam-se responsáveis por todos os setores da sociedade.

O que antes era feito apenas com papelão, isopor ou argila, agora torna-se também digital. A cidade construída pelas crianças fica ainda sobre uma mesa no canto da sala, mas a turma pode construir muitas outras cidades, sem ocupar espaço físico nem ser desgastada pelo manuseio, agora no meio digital.

Através do Città, a criança constrói prédios e vias, modela terrenos, troca cores e apaga os objetos que não servem mais. Também está sendo testado um agente inteligente para questionar a criança sobre a sustentabilidade da cidade (ver seção 4). Além disso, a cidade poderá ser construída em rede e ainda através do navegador web (ver seção 5). 
O Città está constantemente sendo reprojetado, uma vez que a equipe de desenvolvimento trabalha integrada com as acadêmicas de pós-graduação da Faculdade de Educação e do Centro Interdisciplinar de Novas Tecnologias na Educação (CINTED) da UFRGS. Essas acadêmicas são integrantes do LELIC, e assessoram as professoras nas escolas atendidas pelo CIVITAS, onde Città é elaborado numa atitude de escuta e análise deste processo.

Nesse sentido, o Projeto Città Cosmopolita é o resultado de um ciclo de dez anos de estudos e ações contínuas executadas no Projeto CIVITAS. Por esse motivo a releitura e reelaboração do Città é uma prática comum nas equipes destes projetos. Nas seções a seguir tem-se mais uma versão otimizada a partir do diálogo entre o mundo computacional e o pedagógico.

\subsection{As primeiras experimentações/impressões do Città em sala de aula}

Depois de algumas apresentações pontuais que ocorreram durante o desenvolvimento do Città na versão Java tivemos a primeira oficina para exploração e reconhecimento do simulador de cidades com um grupo de professoras do quarto ano de um dos municípios em que desenvolvemos o Projeto Civitas ${ }^{3}$.

No decorrer dessa experimentação nos foi possível perceber alguns detalhes importantes que precisavam ainda ser ajustados no simulador como a cor do objeto praça, o zoom e a colocação de alguns objetos que acusavam sobreposição falando mais tecnicamente.

Por outro lado percebemos o encantamento e a empolgação das professoras ao experimentarem o simulador e suas possibilidades fazendo vários questionamentos sobre como poderiam levar para seus alunos o simulador inserindo-o no cotidiano da sala de aula como mais uma ferramenta que poderia auxiliar na construção da cidade imaginária/virtual da turma.

Sanados os pontos apontados pelas professoras, uma nova versão do simulador foi disponibilizada para as escolas e em seguida foi apresentado aos alunos que fizeram várias explorações no simulador.

Segundo o relato que obtivemos os alunos acharam extremamente importante a presença dos netbooks que fazem parte dessa proposta na sala de aula para a realização de pesquisas e da criação da cidade imaginária.

Com pressupostos para a utilização dessa ferramenta temos alguns critérios que consideramos muito importantes para a formação e aprendizagem dos alunos que têm acesso ao Città, entre eles, a cooperação que acontece desde quando os alunos fazem uso da mesma máquina em grupos de dois ou três discutindo os objetos que vão fazer parte de sua cidade; o respeito pela opinião e entendimento do outro sobre as coisas quando precisam

3 CIVITAS: Cidades Virtuais Tecnologias para Aprendizagem e Simulação. Projeto de Pesquisa e Formação CNPq, FINEP, UFRGS, SESU-MEC. O Civitas é desenvolvido na Educação Infantil e até os $5^{\circ}$ anos do Ensino Fundamental de escolas municipais da cidade de Estrela, nesse caso especificamente, mas já foi desenvolvido também em outros municípios desde sua criação como Cruzeiro do Sul, Mato Leitão, Venâncio Aires e Sobradinho, todas situadas no Rio Grande do Sul. Professores e alunos interagem cooperativamente na tomada de decisões e no planejamento de uma cidade virtual, bem como na definição de normas de convivência urbana em seus aspectos socioambiental, histórico-cultural, ético-estético e político-econômico, gerando subsídios para reflexão crítica, tanto dos conteúdos curriculares quanto dos valores implicados. 
negociar e abrir mão de uma intenção que possuíam em prol da opinião do colega; a solidariedade e o respeito à diversidade quando pensam na importância de construir uma cidade que acolha os diferentes e seja acessível a todas as pessoas que lá decidirem morar; a sustentabilidade ao planejarem uma cidade economicamente viável e ambientalmente sustentável evitando desmatamento, poluição da natureza e dos mananciais de água, desperdício de energia; ainda sobre o quesito respeito podemos destacar a preocupação com o espaço do outro e suas necessidades evitando invadir o terreno do vizinho ou mesmo construir em espaços que não são permitidos porque podem colocar a vida da cidade em risco ou comprometer a saúde dos moradores.

Entre esses pressupostos apontados buscamos durante a utilização do simulador orientar as professoras e professores para que estejam sempre atentos e acompanhando as ações das crianças para que elas percebam a importância de respeitar as regras estabelecidas e, com isso, viabilizando a vida e o convívio na cidade e, sempre que houver desentendimentos ou discordâncias que possam parar para pensar as causas que levaram a esse fato buscando juntos, ouvindo a opinião e posicionamento uns dos outros resolver o impasse da melhor forma.

A partir das experimentações realizadas em sala de aula com o simulador e os registros das crianças percebemos o quanto o mesmo contribuiu para o enriquecimento dos estudos da cidade e das práticas em sala de aula.

Os alunos demonstraram grande interesse e criatividade nas experimentações realizadas criando cidades com os mais diversos temas entre eles Cidade dos Fantasmas e Cidade dos Robôs. Além da produção da cidade imaginária física confeccionada com sucatas e da cidade virtual idealizada no simulador utilizaram outras ferramentas digitais como máquina fotográfica, gravador de voz e interação virtual através do Forchat contanto para as outras turmas o que vinha acontecendo na cidade que haviam criado e recebendo informações dos colegas sobre os fatos ocorridos em suas cidades.

As primeiras impressões expressas tanto pelos alunos como pelas professoras nos motivaram muito, pois além explorarem todos os recursos do simulador nos sugeriram vários acréscimos para a versão que estamos programando em Blender.

\subsection{Módulo de Interface}

A interface do Città foi totalmente remodelada e seus objetos tridimensionais foram redesenhados frente à versão anterior. Com base nos relatos de experiências com as crianças das escolas nas quais o Città foi apresentado, percebeu-se que havia necessidade de melhorar a interface gráfica primeiramente para facilitar a compreensão.

Após diversas discussões ao longo do tempo, foi decidido que além de simplificar a interface, haveria necessidade também de uma revisão e renovação geral da interface gráfica. Foi adotada a ideia de tornar a navegação dos menus clara através de imagens apenas, já que palavras muitas vezes complicadas não eram compreendidas pelas crianças, o que restringia às crianças algumas opções de maneira inconsciente.

O menu agora está menor e mais intuitivo, na lateral direita da tela em transparência (veja figura 1). Assim, ocupa menos espaço de jogo e abre em cascata de acordo com a seleção dos botões principais. A figura 2 ilustra um dos itens simplificados na nova interface com a opção para sair do jogo, que antes necessitava dois passos (à esquerda da figura) e agora é em apenas um (à direita). 

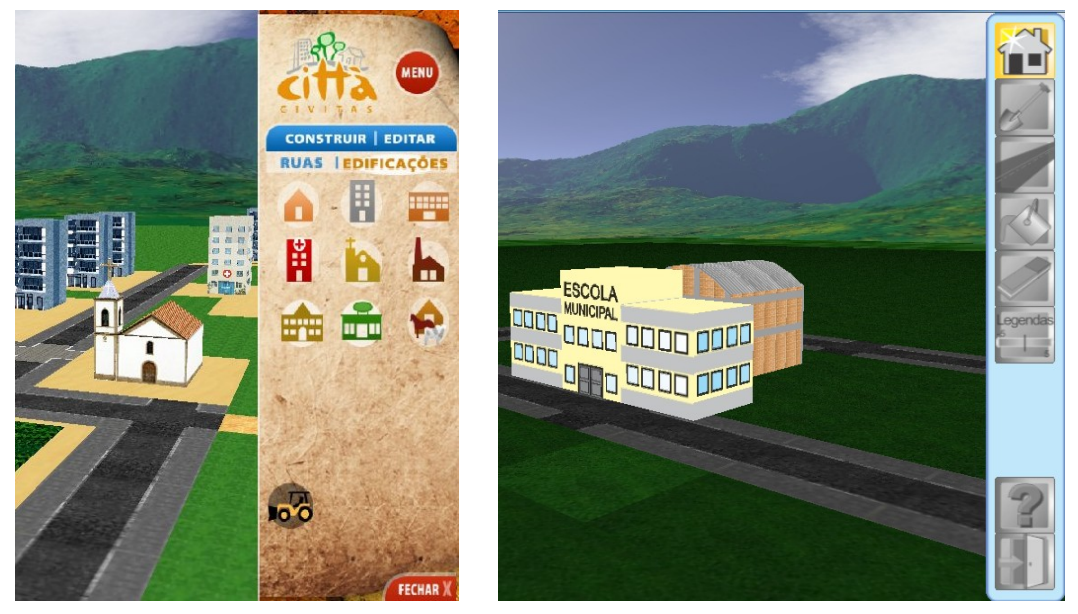

Figura1 -Menuna versãoanterior(à esquerda)e remodelado(à direita).

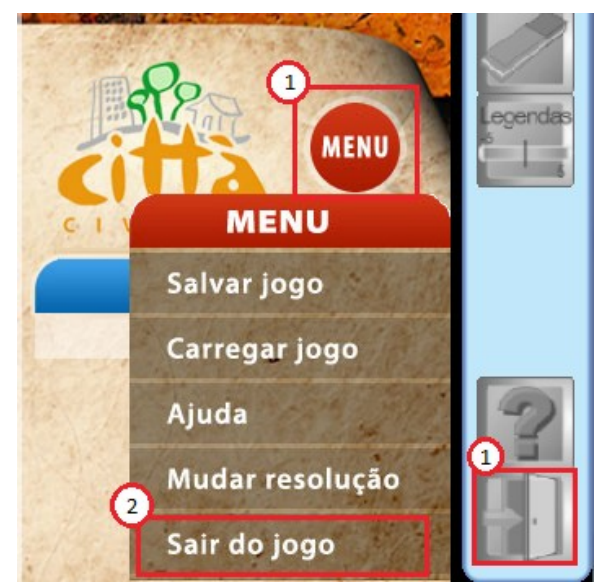

Figura2-Comparaçãodas interfaces:à esquerda, interfaceantiga;à direita, interfacenova.

Ao implementar a nova interface, notou-se as limitações que a falta de conhecimento sobre a engine gráfica e bibliotecas não recentemente atualizadas iriam implicar em futuras atualizações mais complexas como animações. Foi considerada a utilização de uma engine completamente diferente, como o Blender (veja seção 5).

\subsection{Banco de Dados}

O banco de dados livre SQLite 4 foi escolhido por ser de fácil distribuição dentro com os pacotes Java do Città. Durante seu desenvolvimento, foi discutido um método mais otimizado de gravação de mapas, que também facilitaria a implementação de um histórico de eventos também mais otimizado. Este novo método consiste em um arquivo de banco de dados para cada mapa, contendo um registro do estado atual do mapa e um registro de eventos.

O registro do mapa serve para uma rápida reconstrução do mundo de jogo, independente de quantas alterações foram feitas até agora naquele mapa. $\mathrm{O}$ registro de eventos grava a "história" daquele mapa, indicando a data de jogo, o tipo do evento (construção/destruição/"biografia da construção") e um texto, descrevendo o evento em detalhes.

Foi definido também o critério de salvamento dos mapas. Os mapas são salvos

4 http://www.sqlite.org 
assim que o jogador decide sair do mapa atual, não há necessidade de navegar menus ou apertar outros botões.

\section{O agente inteligente Maga Vitta}

Durante a construção da cidade virtual, o aluno conta com auxílio de um agente que observa suas ações no ambiente virtual. $\mathrm{O}$ agente inteligente, encorporado como uma personagem chamada Maga Vitta, não intervém na construção da cidade, mas está sempre atenta para indagar, aconselhar, informar e provocar reflexões sobre os processos de construção da cidade.

Além disso, Maga Vitta é um agente que possui como padrão interno estar eternamente preocupado com a ecologia: ao memorizar ações contra o equilíbrio ecológico, adverte sobre possíveis tragédias ambientais. Em sua interação com o jogo Città, Maga Vitta tem um motor de inferência que trabalha em conjunto com um módulo de conversação.

\subsection{Inferência, diálogo e estados afetivos}

A agente Maga Vitta é a consciência do jogo Città, promovendo a regulação do sistema ecológico. A sua proposta não é realizar a orientação direta, mas provocar ações internas no aluno de forma a fazê-lo se preocupar com a situação indicada no momento do jogo. Dependendo da gravidade da situação, indicada pelo nível de equilíbrio da variável de ambiente, e ainda da prioridade do elemento que está sendo considerado, é indicado ao módulo de diálogo a importância e nível de expressividade que o agente terá que executar.

As variáveis de ambiente são relativas aos produzíveis e consumíveis na cidade virtual, correspondendo ao quanto é produzido ou gasto por cada objeto pertencente à ao jogo. Os objetos criados para composição da cidade virtual são: casa, prédio, escola, hospital, igreja, fábrica, prefeitura, mercado, fazenda, árvore, ETA (Estação de Tratamento de Água), usina eólica, aterro sanitário, ETE (Estação de Tratamento de Esgoto), UTLH (Unidade de Tratamento de Lixo Hospitalar).

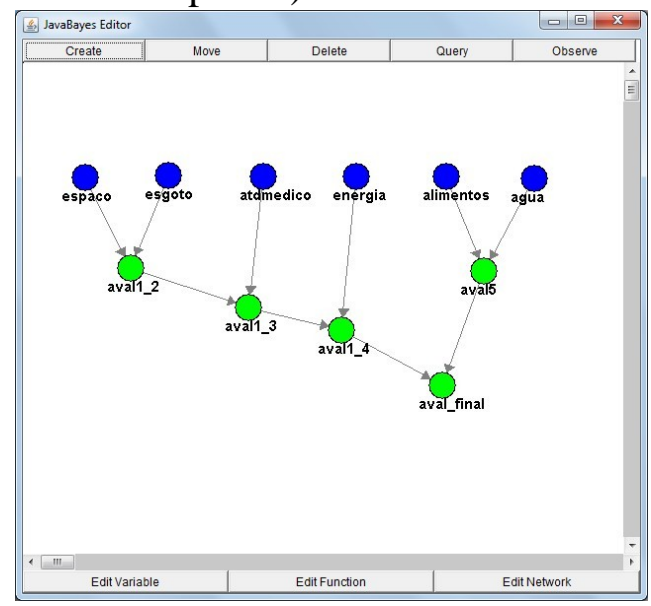

Figura3-Projetode inferênciano JavaBayes.

Uma rede bayesiana projetada para tomada de decisão das variáveis de ambiente, as quais têm os valores aplicados nos nodos superiores e a resposta é obtida no nodo de nível mais baixo, conforme mostra a figura 3 , obtida a partir da modelagem realizada com o 
sistema de software livre JavaBayes ${ }^{5}$. Este software livre foi incorporado ao projeto Java do Città, obtendo-se sucesso no cálculo das variáveis de ambiente e obtenção das decisões necessárias às intervenções da Maga Vitta.

Atualmente está sendo trabalhado o uso do raciocínio bayesiano juntamente com o esquema de Raciocínio Baseado em Casos (RBC) elaborado para o diálogo da Maga Vitta. Como parâmetro, utiliza-se o trabalho de [Pavón et al, 2009], que o qual aborda a inferência bayesiana na busca do conjunto de soluções dentro de um sistema RBC.

Desta forma, foram pesquisadas implementações de RBCs em software livre, para composição ao projeto do jogo Città. A plataforma RBC que convergimos para integração ao nosso projeto foi a jCOLIBRI - CBR Framework ${ }^{6}$. Na fase atual de desenvolvimento está ocorrendo a integração do JCOLIBRI com o chat de diálogo entre a criança e a Maga Vitta.

Além dos módulos de inferência e diálogo, a Maga Vitta também está projetada para ter capacidade emotiva e de personalidade [Konzen et al, 2011]. Para tanto, está sendo estudado o modelo de emoções OCC, [Ortony, Clore e Collins, 1988] e o modelo Big Five, de representação de traços de personalidade [John, 1999]. Como este módulo está em iniciando seu desenvolvimento, ainda ocorrerá o aprofundamento destes e outros modelos para posterior implementação. Na figura 4 pode-se observar um estudo gráfico dos diferentes estados emocionais da Maga Vitta.

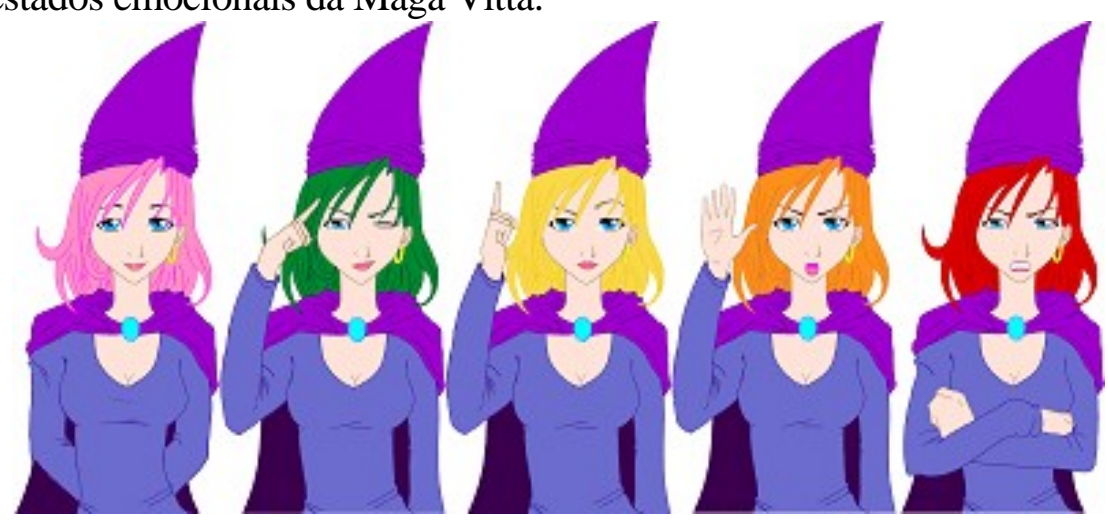

Figura4-Estadosemocionaisda MagaVitta.

\subsection{Reconhecimento e síntese de fala}

O módulo de voz consiste no reconhecimento de voz da criança usuária do Città e a síntese do agente inteligente Maga Vitta.

O reconhecimento de voz foi continuado com o aperfeiçoamento do modelo lingüístico e teste de palavras para reconhecimento, sempre dentro do modelo dos sistemas de software livre $H_{T K}^{7}$ (treinamento estocástico) e $J_{u l i u s}{ }^{8}$ (reconhecimento de voz). Neste sentido, foram feitas interações com bolsistas do Projeto Comunica ${ }^{9}$, do Instituto de Informática da UFRGS, e com membros do Projeto FalaBrasil ${ }^{10}$ da UFPA, no sentido de otimizar o reconhecimento.

A integração do módulo de reconhecimento de voz através do Julius ocorreu

5 http://sourceforge.net/projects/jbnc

6 http://sourceforge.net/projects/jcolibri-cbr

7 http://htk.eng.cam.ac.uk

8 http://julius.sourceforge.jp/en index.php

9 http://comunica.conexum.com.br

10 http://www.laps.ufpa.br/falabrasil 
parcialmente através da inserção de botões de controle de gravação de voz ("Começar gravação" e "Parar gravação") na interface do chat com a Maga. No entanto, o módulo de reconhecimento de voz não está funcional em conjunto com os outros módulos. Foi cogitado o uso de uma ferramenta semelhante ao grep (GNU Project) para buscar as palavras-chave capturadas pelo Julius e repassá-las ao assistente do jogo (veja figura 5).

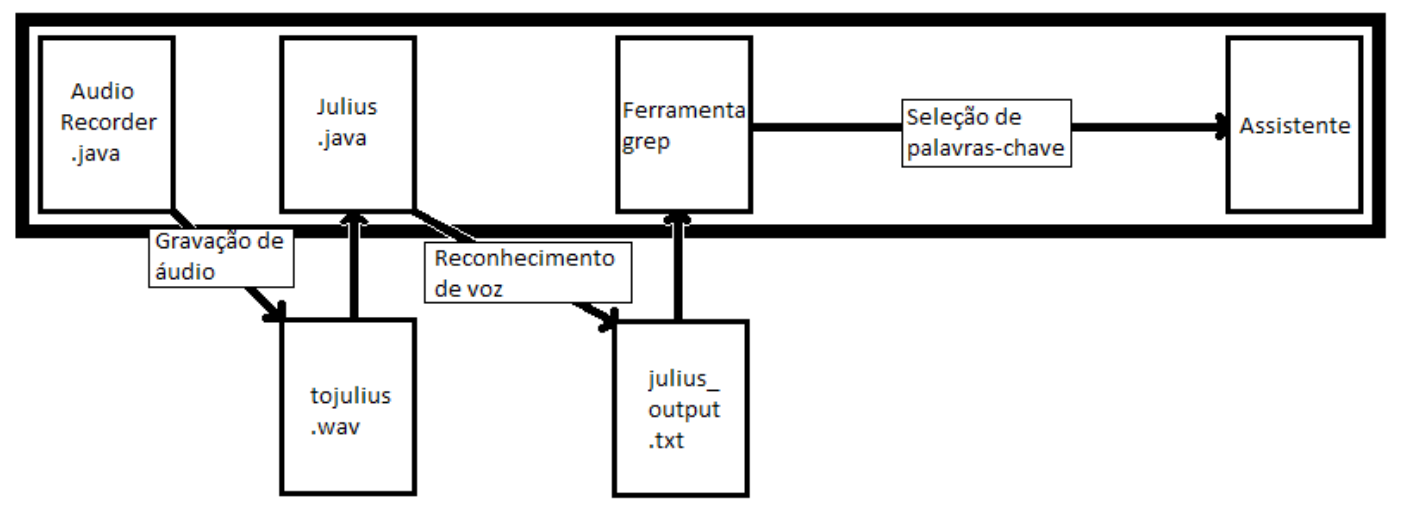

Figura5-Sequênciade chamadasdoJuliusno Città.

Quanto à síntese de fala, utilizamos o sistema de software livre MaryTTS ${ }^{11}$, também com apoio da equipe do Projeto Comunica, que desenvolveu um modelo acústico com voz feminina, adequada à Maga Vitta. MaryTTS é uma solução completa e configurável para síntese, incluindo a construção do modelo acústico para voz, o léxico de fonemas e a parametrização de itens como a prosódia (entonação) e velocidade de leitura (duração). Ele utiliza um padrão de serviço internet (WebService) para receber um texto e enviar um arquivo de áudio. Ao iniciar o Città é necessário ativar o servidor (maryserver) e, quando necessário, apenas solicitar o arquivo de áudio para determinada frase. Para tanto, foi adicionada uma chamada de sistema para o servidor, ao início do Città, e uma classe Java (MaryClientUser) para a síntese, quando esta for solicitada.

Testes realizados apenas com a classe cliente (MaryClientUser) possibilitou a geração de uma janela para testes, como mostra a figura 6 .

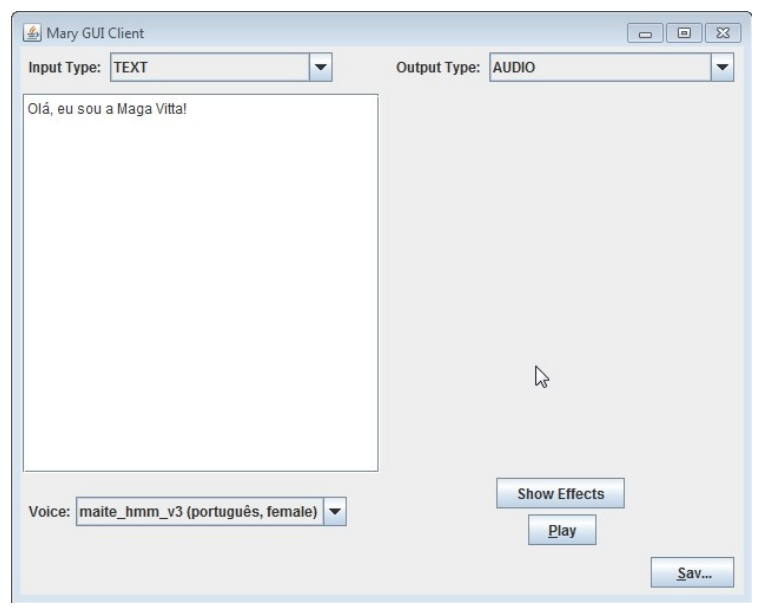

Figura6-Janelade testesno clienteMaryTTS

Os modelos acústicos de síntese para o Português que vêm com o MaryTTS são primitivos, proporcionando uma voz visivelmente mecânica e de difícil audição. Neste

11 http://mary.dfki.de 
sentido, foi necessária a gravação de mais de 600 frases (locução feminina) e geração de um léxico de 700 palavras com sua anotação fonética para treinamento do modelo acústico. Este modelo proporcionou uma síntese com boa audição, embora ainda possa melhorar, através do ajuste de parâmetros de saída do MaryTTS.

\section{Nova engine Blender}

A equipe do Città já trabalhava com o software livre Blender para modelagem dos objetos em 3D e partimos para a linguagem Python (já integrada nas versões do Blender). Pois assim seria possível excluir boa parte de problemas que tivemos de compatibilidade com programas e teríamos ainda uma ferramenta mais potente, estável e que poderíamos ter mais controle sobre o próprio desenvolvimento do software, sem o uso de diversos programas para adaptação.

Outra funcionalidade que achamos muito interessante é a possibilidade de embutir animações. Uma ideia que desde o começo do projeto era fazer a integração da Maga Vitta com algum tipo de animação ou 3D. Hoje isso é possível.

Acabamos com problemas de leitura de texturas ou materiais. Agora tem-se a possibilidade de trabalhar com a OpenGL plenamente e utilizam-se sistemas de shaders complexos para tratamento dos modelos em tempo real de jogo, com iluminação, sombra, luz, mapeamento alpha, etc.

A partir de agora o Città será mais estável, sendo definido na programação a quantidade de frames que irá rodar o jogo. E o jogo passará a rodar em Windows, Linux e Mac sem nenhum problema, além de ser possível seu uso em navegadores web.

Pontos decisivos para escolhermos o Blender:

- Programa em software livre;

- Motor de jogo integrado com linguagem em Python - aqui nós optamos por termos alguns problemas de incompatibilidade com Java e também por ser mais estável para diversas configurações de máquinas;

- Programa leve, rápido e eficiente para nossa proposta;

- Agilidade no processo do jogo, pois temos todas as ferramentas em um programa. Isso nos auxilia para melhor integração dos bolsistas entre si e com o projeto;

- Sistema conhecido pelos bolsistas do projeto, pois já era utilizado para desenho dos objetos 3D, e a linguagem integrada Python também familiar para a equipe;

- Possibilidade de construção da abordagem multijogador, a exemplo do jogo $\mathrm{WSAG}^{12}$, e a constituição de redes de cidades;

- Existência de plugins para rodar um .blender em navegadores web, como o Burster ${ }^{13}$.

Dentro dessa nova concepção do Città no Blender, estão sendo previstos novos recursos como a leitura de dados de relevo reais para modelagem do terreno da cidade. Isso significa que uma cidade poderá ser reconstruída com os dados reais em relação ao seu relevo. Outro recurso previso com o multijogador e com a interface web é a geolocalização. Através dela será possível o mapeamento das diferentes culturas, e da localização dos

12 http://www.oldjim.ch/WSAG

13 http://geta3d.com 
grupos de alunos, suas escolas e cidades (imaginadas ou reais).

\section{Considerações finais}

O Projeto Città Cosmopolita é uma parceria entre a empresa CONEXUM e o LELICFACED-UFRGS, para desenvolvimento de novas tecnologias digitais que promovam a inovação nos processos educacionais. Nesta parceria é desenvolvido o software livre Città, voltado à construção de cidades imaginadas por estudantes do $4^{\circ}$ ano do ensino fundamental, dentro do contexto do Projeto CIVITAS.

Città é um software desenvolvido com pedagogas e voltado à aplicação como ferramenta de apoio à metodologia CIVITAS. Neste sentido, Città está sempre evoluindo, na interação tanto com as crianças usuárias quanto as professoras que refletem sobre a aplicação desta ferramenta sobre o pensar, sentir e agir no contexto educativo.

Do ponto de vista tecnológico, desenvolvem-se os recursos de interação gráfica, textual e vocal. Ainda são analisadas formas de monitoramento das ações do jogo de simulação e do banco de dados de interações para tomada de decisões de diálogo.

Os novos dispositivos proporcionados pelo Blender estão resultando em interações mais ricas e complexas, e, em contraponto, mais fáceis de implementar computacionalmente. Uma vez que existe uma gama de funcionalidades já incorporadas no Blender, a rapidez e o efeito obtidos nas ações do Città são muito superiores aos que foram produzidos nos últimos anos.

As aplicações que podem ser derivadas desse processo são muitas. Além de simulações que podem ser feitas com jogos empresariais, voltados à educação de adultos nas relações de trabalho, há possibilidade da criação de novos tipos de redes de convivência em ambientes tridimensionais, inclusive na internet e com dispositivos móveis.

O uso de assistentes que possibilitam o diálogo é um dado relevante, não somente do ponto de vista educacional, mas para qualquer um que queira ter suas tarefas facilitadas junto ao computador ou outro dispositivo eletrônico. Sistemas de monitoramento com diálogo, principalmente envolvendo diversas mídias combinadas de imagem, texto e voz, podem vir a compor uma nova concepção de interface.

O desenvolvimento do Città Cosmopolita vem comprovando que a pesquisa computacional caminha de mãos dadas com o estudo de campo. Apesar da formação profissional dar um enfoque estanque aos conhecimentos acadêmicos, toda a relação de pesquisa e desenvolvimento dá-se na interação de diferentes áreas. No caso deste projeto, o diálogo entre Educação e Computação é essencial para o adequado uso do computador como instrumento de qualificação do cidadão do amanhã.

Agradecimentos. O projeto Città Cosmopolita é financiado com o apoio do CNPq - Conselho Nacional de Desenvolvimento Científico e Tecnológico. Agradecemos a toda a equipe do Projeto CIVITAS por sua assessoria a este projeto, em especial a coordenadora do LELIC profa. Dra. Margarete Axt (FACED/CINTED - UFRGS). Também agradecemos a parceria dos professores Andréa Konzen (UNISC), Marcio Martins (UNIPAMPA) e Tânia Hetkowski (UNEB).

\section{Referências}

Albuquerque, R. M. ; Cruz, D. M. ; Azevedo, V. A. (2009) Jogos eletrônicos na escola: uma experiência educativa com o LinCity-NG. In: VIII Simpósio Brasileiro de Jogos e 
Entretenimento Digital, 2009, Rio de Janeiro. Proceedings do VIII Simpósio Brasileiro de Jogos e Entretenimento Digital, 2009 v. 1. p. 57-60.

Araújo, C. de F. M.; Simon, E. B. (2008) Objetos de aprendizagem em educação a distância: uso de jogos educacionais no estilo RPG (Role-Playing Games) digitais. In: RevistaPaidéi@, Vol. 1, No 1.

Axt, M. e Martins, M. A. R. (2008) Coexistir na diferença: De quando a formação em serviço pensa modos de habitar a sala de aula. In: Trindade, Iole Maria Faviero. (Ed), Múltiplas Alfabetizações e Alfabetismos, pp. 133-158, Editora da UFRGS, Porto Alegre, 1 ed., v. 1.

Guterres, J. O.; Eichler, M. L.; Del Pino, J. C. (2003) A usabilidade de Carbópolis, um software livre para a educação ambiental.. Tecnologia Educacional, Rio de Janeiro, v. 32, p. 69-82.

Hornes, A.; Grachinski, L.; Silva, S. C. R.; Koscianski, A. (2009) Os jogos computacionais no ensino de física. In: VII Encontro Nacional de Pesquisa em Educação em Ciências, 2009, Florianópolis, SC, Brasil.

John, Oliver P. (1999) “The 'Big Five' factor taxonomy: Dimensions of personality in the natural language and in questionnaires", In: Handbook of personality: Theory and research. Edited by Lawrence A. Pervin, Guilford.

Konzen, A. A. ; Braitback, O. L. B.; Kist, L. ; Anjos, A. R. ; Moraes, L. D.; Lima, C. I. L.; Müller, D. N.; Axt, M. (2011) Maga Vitta: agente conversacional aplicado ao jogo educacional Città. In: Simpósio Brasileiro de Informática na Educação, Aracajú.

Oliveira, C. (2011) A contribuição dos jogos de simulação na aprendizagem: uma experiência com jogo The Sims. In: $V$ Colóquio Internacional "Educação $e$ Contemporaneidade". São Cristóvão, 21 a 23 de setembro.

Oliveira, O. L. B. de, Müller, D. N., Remião, J. A. A., Silveira, P. D., Ferreira Filho, R., Martins, Márcio A. R. e Axt, Margarete. (2009) CIVITAS: cidades virtuais na educação. In: Andrea S. Charão et all. X workshop de Software Livre - FISL 2009. Porto Alegre, pp. 141-146.

Ortony, A., Clore, G. L. e Collins, A. (1988), "The cognitive structure of emotions", Cambridge University Press.

Pavón, R., Díaz, F., Laza, R. e Luzón, V. (2009) "Automatic parameter tuning with a Bayesian case-based reasoning system. A case of study" In: Expert Systems with Applications 36, pages 3407-3420, Elsevier.

Pereira, F. L. F; Araújo, S. de L.; Holanda, V. C. C. de. (2011) As novas formas de se ensinar e aprender geografia: os jogos eletrônicos como ferramenta metodológica no ensino de geografia. In: Geosaberes, Fortaleza, v. 2, n. 3, p. 34-47, jan. / jul.

Tavares, R. B. (2012) O Jogo da Geografia: SimCity como recurso didático no Ensino de Geografia e no Planejamento de cidades. Sistema Pec de Ensino. Disponível em http://www.sistemapec.com.br/portal-da-educacao/artigos/o-jogo-da-geografia Acesso em maio/2012.

Tarouco, L.M.R. ; Fabre, M. ; Roland, L. C. ; Konrath, M. L. P. (2004) Jogos educacionais. RENOTE. Revista Novas Tecnologias na Educação, Porto Alegre, v.2, n.1, p. 1-7. 